\title{
Ensino de história, direitos humanos e narrativas: potencialidades da pesquisa-formação ${ }^{1}$
}

History teaching, human rights and narratives: potentialities of research-formation

Felipe Rodrigues da Silva* Raquel ALS Venera**

\section{Resumo}

Este artigo tem como objetivo revisitar as trajetórias da educação em e para os direitos humanos no Brasil e discutir uma possibilidade prática de formação de professores de História em e para os direitos humanos a partir da ferramenta de pesquisa-formação denominada ateliê (auto)biográfico. $\mathrm{O}$ ateliê é parte de uma pesquisa de doutorado em andamento e os atores da pesquisa são professores de História em formação e bolsistas do Programa Institucional de Bolsas de Iniciação à Docência (Pibid). Iniciamos o trabalho refletindo sobre os caminhos que a educação em e para os direitos humanos tem trilhado nas últimas décadas no Brasil e como estas trajetórias implicam no ensino de história. Em seguida, apresentamos e discutimos $o$ ateliê para defender a ideia de que ele tem a capacidade de promover reflexões e práticas relacionadas aos direitos humanos e contribuir com a formação para a docência no ensino de história.

Palavras-chave: ensino de História; narrativas; direitos humanos.

\section{Abstract}

This article aims to revisit the trajectories of education in and for human rights in Brazil and discuss a practical possibility of training history teachers in and for human rights from the researchtraining tool called (auto)biographical studio. The workshop is part of an ongoing doctoral research and the research actors are history teachers in training and PIBID fellows. We begin by reflecting on the paths that education in and for human rights has followed in recent decades in Brazil and how these trajectories imply in the teaching of history. Next we present and discuss the workshop to defend the idea that it has the ability to promote reflections and practices related to Human Rights aned contribute to training for teaching in history teaching.

Keywords: History teaching; narratives; human rights.

\footnotetext{
* Secretaria de Educação, Joinville, SC, Brasil; Secretaria de Estado de Educação de Santa Catarina, Florianópolis, SC, Brasil. felipe@yahoo.com.br

** Universidade da Região de Joinville (Univille), Joinville, SC, Brasil. raquelsenavenera@gmail.com
} 
Discutimos neste artigo alguns desdobramentos da pesquisa de doutorado intitulada "Narrativas de vida e formação docente: bolsistas do Pibid em História e suas identificações com os direitos humanos"2, cujo objetivo central é compreender, nas narrativas de vida dos estudantes em formação, como suas subjetividades são construídas sensíveis aos direitos humanos a partir da seguinte questão: "Como as narrativas de vida dos estudantes de história e bolsistas do Pibid evidenciam construções subjetivas de sensibilidade aos Direitos Humanos?". Essa ideia de pesquisa nasceu de nossas inquietações profissionais e pessoais relacionadas ao ensino de História, à formação de professores, à pesquisa (auto)biográfica e aos direitos humanos, pois ambos trabalhamos com formação de professores, participamos de grupos de pesquisas que trabalham com narrativas de vida e somos professores de História.

A escolha de bolsistas do Programa Institucional de Bolsas de Iniciação à Docência (Pibid) como personagens da pesquisa se dá por conta da participação na supervisão desses professores em formação em uma escola de educação básica. essa experiência de participação orgânica no Pibid nos fez compreender a amplitude da potência experiencial e formativa do programa e a necessidade de sua defesa permanente. Consideramos que, em pesquisa, essa defesa pode acontecer pela criação de evidências da relevância do programa, por isso esse é um dos propósitos da investigação em desenvolvimento.

A interface temática de discussão pautada nos direitos humanos também tem uma motivação (auto)biográfica relacionada a ataques de sujeitos ligados a grupos políticos conservadores, a nossas atividades de docência na educação básica, ao indício de que estamos em tempos de resistência e à defesa de uma educação e um ensino de História em e para os direitos humanos. Ademais, partimos da hipótese de que a sensibilidade aos direitos humanos, que, em um olhar apressado, pode ser vista como um pressuposto inerente a estudantes de História, tem ligação com as histórias de vida e formação desses atores e a pesquisa busca compreender, com base nas teorizações sobre investigação-formação de Marie Christine Josso (2010, p. 254), o que aconteceu na vida desses estudantes que os influenciou a se tornarem professores de História e qual é a relação, ou importância, do que chamamos de direitos humanos nessa trajetória (auto)biográfica de formação.

Por se tratar de um grupo de atores que são professores em formação, o 
recurso metodológico escolhido dentro do leque de possibilidades que a pesquisa (auto)biográfica oferece para a composição das narrativas de vida foi o ateliê (auto)biográfico. Desenvolvemos o ateliê tendo como referência as experiências de pesquisa de Christine Delory-Momberger (2014, p. 339) nas suas oficinas biográficas de projeto e de Marie Christine Josso (2010, p. 249) no seu curso-seminário "História de Vida em Formação".

Tendo como base a pesquisa apresentada acima, questionamos neste artigo: "Quais são os caminhos da educação em e para os direitos humanos no Brasil?"; “Como essa trajetória se desdobra no ensino de História?”; e "Quais potencialidades de formação em e para os direitos humanos o ateliê (auto)biográfico pode viabilizar no processo de preparo profissional de futuros professores de História?”. Tendo apresentado as problemáticas deste artigo, salientamos que entendemos que os ativismos em favor dos direitos humanos e da educação em e para estes construíram uma trajetória documental, legislativa e curricular bastante progressista. Assim, defendemos a ideia de que, do ponto de vista prático, o ateliê (auto)biográfico, como um método de pesquisa-formação, tem a capacidade de promover reflexões e práticas relacionadas aos direitos humanos e contribuir com a formação para o ensino de História.

Para abranger os questionamentos elencados acima, dividimos o texto em quatro seções. Na primeira, cujo título é "Educação e $(\mathrm{m})$ e para os direitos humanos no Brasil", revisitamos os caminhos que a educação em e para os direitos humanos têm trilhado nos últimos anos no Brasil, com destaque para os documentos oficiais em esfera federal. Depois, na segunda seção denominada "Ensino de História, currículo e direitos humanos no Brasil", discutimos como as trajetórias da educação em e para os direitos humanos implicam no ensino de História, levando em conta principalmente o contexto curricular nacional recente. Por fim, consideramos os temas trabalhados na primeira e segunda parte e apresentamos o ateliê (auto)biográfico como potência de formação para os direitos humanos em um investimento diante dos desafios da formação de professores de História sensíveis aos direitos humanos. Apresentamos o ateliê (auto)biográfico e discutimos suas potencialidades formativas. Fechamos o artigo com algumas considerações sobre ensino de História, formação, narrativas e direitos humanos. 
EdUCAÇÃo E(M) E PARA OS DIREITOS HUMANOS NO BRASIL

Do ponto de vista do estado brasileiro, a preocupação com a ideia e a prática dos direitos humanos é relativamente recente. A despeito do Brasil ter sido um dos signatários da Declaração Universal dos Direitos Humanos da Organização das Nações Unidas (ONU), votando favorável ao seu texto já na assembleia que ratificou o documento em 1948, essa discussão só foi levada em conta de fato em nosso país nos anos 1980.

É necessário salientar que a pauta dos direitos humanos é amplamente requisitada nas décadas da ditadura civil-militar brasileira a partir de movimentos sociais, grupos políticos, sindicatos, agremiações estudantis, intelectuais, artistas e cidadãos em geral que, na luta contra o autoritarismo, valeram-se de argumentações relacionadas a direitos humanos que

foram incorporadas ao campo das lutas políticas, dos debates, das denúncias, das matérias de jornal, de teses acadêmicas. A temática passou a disputar espaço no discurso hegemônico, no plano nacional. A repressão da ditadura militar permitiu que fosse conquistado um espaço para o tema dos direitos humanos, mesmo nos órgãos de imprensa conservadores. (Sader, 2007, p. 81).

Esta movimentação, no entanto, não ocorria a partir do Estado Brasileiro que, pelo seu cunho autoritário, tratava de criminalizar os discursos que evocavam a noção de direitos humanos. Esse trabalho de construção de hegemonia discursiva foi tão impetuoso que o senso comum de que "direitos humanos só servem para defender bandidos” ainda é bastante recorrente, mesmo após mais de três décadas após o fim do regime ditatorial. Como é sabido, na oralidade e nas memórias sobre os mortos da ditadura civil-militar no Brasil, essa noção surgiu do fato de que os presos políticos da ditadura eram defendidos e encontravam apoio contra as arbitrariedades do regime por movimentos e círculos de sujeitos relacionados aos direitos humanos, que eram denominados "bandidos" por serem ativistas que lutavam contra as violências do autoritarismo de estado.

As lutas e conquistas de redemocratização e a composição de uma nova Constituição Federal na década de 1980 contribuíram para o crescimento do debate sobre direitos humanos no Brasil. A Constituição de 1988 (Brasil, 2015), também conhecida como "Constituição Cidadã", tem como marca a garantia de 
direitos individuais e coletivos nos âmbitos civil, social e político, corroborando a ideia de que as "constituições democráticas cumprem um papel fundamental no desenvolvimento da cultura dos direitos humanos", conforme indicam Maués e Weyl (2007, p. 109), os quais também propõem a seguinte reflexão:

A pauta mais importante estabelecida pelas Constituições, para lograrem esse objetivo, são os direitos fundamentais. Ao reconhecê-los como direitos inalienáveis de todos os cidadãos e cidadãs, o Estado incorpora o conteúdo dos direitos humanos ao seu ordenamento jurídico e se compromete a dispor de um conjunto de meios e instituições para garanti-los. Assim, os direitos humanos não são compreendidos como criações do Estado, mas como obra da própria sociedade que, por meio de seus representantes, estabelece os direitos que fundamentam e legitimam o Estado.

A lógica do ordenamento jurídico estatal parte do princípio de supremacia constitucional em que "somente são válidas aquelas normas que estão de acordo com a Constituição, o que faz com que todas as leis e os demais atos do poder público devam respeitar e promover os direitos humanos/fundamentais" (Maués; Weyl, 2007, p. 109). Além disso, esses princípios são intangíveis, pois não podem ser abolidos, nem mesmo mediante emenda constitucional. Surge, assim, um precedente juridicamente viável para uma educação em e para os direitos humanos, já que a legislação de educação, tal como qualquer outra, precisa seguir os preceitos constitucionais.

A gênese do debate sobre educação em e para direitos humanos no Brasil também aconteceu nos anos 1980, no contexto de luta pelo fim da ditadura civil-militar, que durou de 1964 a 1985 . Movimentos sociais e organizações não governamentais (ONGs) vinham se movimentando desde meados da década de 1970 em várias partes da América Latina, com destaque para o Instituto Interamericano de Direitos Humanos (IIDH), criado em São José, na Costa Rica, em 1980. O contexto de surgimento é o mesmo: o ativismo dos movimentos sociais em luta por liberdade realizando experiências populares e não formais de educação. De acordo com Silva e Tavares (2013, p. 51):

No continente sul-americano, a educação em direitos humanos (EDH) é uma prática recente, que surge no contexto das lutas e movimentos sociais de resistência contra o autoritarismo das ditaduras. As primeiras experiências de educação 
em direitos humanos, segundo os registros do Conselho de Educação em Direitos Humanos da América Latina (CEAAL) e do Instituto Interamericano de Direitos Humanos (IIDH), concretizam-se por meio de experiências de educação popular e de educação não formal.

No Brasil, conforme relata a professora Nair Heloisa Bicalho de Sousa (2017, p. 88-89),

Os anos 1980 foram marcados pela presença de ações de promoção e defesa dos direitos humanos que se combinaram com a formação de educadores populares e integrantes do sistema de ensino formal. Vários deles integraram os cursos interdisciplinares e seminários do Instituto Interamericano de Direitos Humanos.

Esse movimento impulsionou seminários, cursos e oficinas em várias regiões do país durante a década de 1980. É importante destacar também a II Conferência Mundial de Direitos Humanos em Viena (1993), que teve o brasil como relator e contribuiu no estímulo da discussão sobre direitos humanos nos âmbitos do poder público e da sociedade civil brasileira (Sousa, 2017, p. 89). A respeito da Conferência, Tosi e Ferreira (2014, p. 48) relatam que

Entre as decisões tomadas pela conferência estava a aprovação do Programa Mundial para a Educação para os Direitos do Homem e para a Democracia, que havia sido aprovado em março do mesmo ano no Congresso Internacional sobrea Educação para os Direitos do Homem e para a Democracia, realizado na cidade canadense de Montreal. Este programa foi retomado em 2004 pela UNESCO, que elaborou um plano de ação para a realização do Programa Mundial para a Educação em Direitos Humanos.

A ONU também promulgou, no âmbito da Conferência de Viena e da Assembleia Geral da ONU de 1994, a "Década da Educação em Direitos Humanos”, entre 1995 e 2004. Foram previstas ações de criação de Comitês Nacionais de Educação em Direitos Humanos e elaboração de planos de ações. Essas orientações de ação da ONU surtiram efeito interessante no contexto brasileiro.

No ano que sucedeu a Conferência de Viena, foi realizado um seminário sobre educação em direitos humanos que culminou na fundação da Rede Brasileira de Educação em Direitos Humanos, com sede no estado de São Paulo, 
que passou a organizar encontros e congressos, com destaque para o Encontro de Educação em Direitos Humanos, realizado em 1995, tendo como enfoque de discussão princípios, metodologias, conteúdos e especificidades da educação em direitos humanos. Foi notório também o I Congresso Brasileiro de Educação em Direitos Humanos, sediado na Universidade de São Paulo (USP), em que se fizeram presentes mais de 1200 educadores(as).

Em 1996, o Ministério da Justiça conduziu o desenvolvimento do Programa Nacional de Direitos Humanos I (PNDH I) e, para dar sustentação institucional a esta nova política pública, visando sua implementação no ano seguinte, foi criada Secretaria Nacional de Direitos Humanos (SNDH), vinculada ao Ministério da Justiça. Na IV Conferência Nacional de Direitos Humanos, realizada em 1999, a pauta de discussão foi a análise do impacto da implementação do PNDH I e a apresentação de uma nova proposta, mais abrangente incluindo a discussão de educação.

Além desses movimentos mais específicos, a Lei no 9.394 (LDB), que estabelece Diretrizes e Bases da Educação Nacional, foi sancionada em meados da década de 1990, que, em consonância com a Constituição Federal, assumiu que a educação nacional deve ser inspirada nos "princípios de liberdade e nos ideais de solidariedade humana, tem por finalidade o pleno desenvolvimento do educando, seu preparo para o exercício da cidadania e sua qualificação para o trabalho", os quais são bastante guiados pelos direitos humanos. Com o passar das décadas, outras discussões relacionadas aos direitos humanos foram sendo incorporadas à LDB, influindo inclusive no ensino de História em nosso país - peculiaridades estas que são discutidas mais detidamente no próximo subtítulo.

As primeiras décadas do século XXI têm manifestado relevantes avanços em termos de reconhecimento da importância e necessidade da educação em e para os direitos humanos por parte do estado brasileiro. Em termos globais, em 2004, a Assembleia Geral da ONU aprovou o Programa Mundial para a Educação em Direitos Humanos, sendo que, no ano anterior, o Brasil já tinha criado o seu próprio Comitê Nacional de Educação em Direitos Humanos (CNEDH), que foi o pontapé inicial para o desenvolvimento de políticas públicas relevantes no campo da educação em e para os direitos humanos, em que o Brasil foi pioneiro na América Latina. 
Para dar suporte às atividades do Comitê Nacional de Educação em Direitos Humanos, foi instalada, em 2004, a Coordenação Geral de Educação em Direitos Humanos (CGEDH), a qual se encarregou de encaminhar sob orientação do Comitê Nacional de Educação em Direitos Humanos a discussão nacional do Plano Nacional de Educação em Direitos Humanos, por meio de seminários estaduais em 25 estados da federação e do Distrito Federal, além de consulta nacional pela internet, resultando na elaboração de uma versão final do Plano Nacional de Educação em Direitos Humanos, lançado em 2007. (Sousa, 2017, p. 90).

É neste contexto, por exemplo, que foram discutidos e publicados o Plano Nacional de Educação em Direitos Humanos (PNEDH), em 2007 (Brasil, 2018), que tem como elemento balizador de seu discurso o Programa Mundial de Educação em Direitos Humanos (PMEDH), cujos princípios são os seguintes:

a) fortalecer o respeito aos direitos humanos e liberdades fundamentais; b) promover o pleno desenvolvimento da personalidade e dignidade humana; c) fomentar o entendimento, a tolerância, a igualdade de gênero e a amizade entre as nações, os povos indígenas e grupos raciais, nacionais, étnicos, religiosos e linguísticos; d) estimular a participação efetiva das pessoas em uma sociedade livre e democrática governada pelo Estado de Direito; e) construir, promover e manter a paz. (ONU, 1997)

Em âmbito brasileiro, os objetivos do PNDEH são:

a) destacar o papel estratégico da educação em direitos humanos para o fortalecimento do Estado Democrático de Direito; [...] f) propor a transversalidade da educação em direitos humanos nas políticas públicas, estimulando o desenvolvimento institucional e interinstitucional das ações previstas no PNEDH nos mais diversos setores (educação, saúde, comunicação, cultura, segurança e justiça, esporte e lazer, dentre outros); [...] h) orientar políticas educacionais direcionadas para a constituição de uma cultura de direitos humanos; [...] k) incentivar a criação e o fortalecimento de instituições e organizações nacionais, estaduais e municipais na perspectiva da educação em direitos humanos; (Brasil, 2018, p. 28-29).

Nessa mesma linha, a Resolução no 1/2012 do Conselho Nacional da Educação (CNE) estabelece diretrizes que devem ser observadas pelos sistemas de ensino e suas instituições, levando em conta os aspectos e dimensões a seguir: 
Art. $4^{\circ} \mathrm{A}$ Educação em Direitos Humanos como processo sistemático e multidimensional, orientador da formação integral dos sujeitos de direitos, articula-se às seguintes dimensões: I - apreensão de conhecimentos historicamente construídos sobre direitos humanos e a sua relação com os contextos internacional, nacional e local; II - afirmação de valores, atitudes e práticas sociais que expressem a cultura dos direitos humanos em todos os espaços da sociedade; III - formação de uma consciência cidadã capaz de se fazer presente em níveis cognitivo, social, cultural e político; IV - desenvolvimento de processos metodológicos participativos e de construção coletiva, utilizando linguagens e materiais didáticos contextualizados; e $\mathrm{V}$ - fortalecimento de práticas individuais e sociais que gerem ações e instrumentos em favor da promoção, da proteção e da defesa dos direitos humanos, bem como da reparação das diferentes formas de violação de direitos. (Brasil, 2012, p. 2).

A mencionada resolução do CNE resultou na publicação do Caderno de educação em direitos humanos (Brasil, 2013a), que evidencia a trajetória da luta por uma educação em e para os direitos humanos no mundo e no Brasil e destrincha os aspectos conceituais, dimensões e princípios e propostas metodológicas de implementação do PNEDH.

Essa conjuntura de acontecimentos, ações estatais e documentos normativos têm desdobramentos no ensino de História em seus diversos âmbitos, da educação básica à formação superior, os quais serão discutidos na próxima seção.

\section{ENSINO DE HistóRIA, CURRÍCULO E DIREITOS HUMANOS NO BRASIL}

Os documentos norteadores e legislativos que abordam a discussão sobre direitos humanos no campo da educação têm repercussões no ensino de História. Nesta seção, refletiremos sobre como as trajetórias da educação em e para os direitos humanos implicam no ensino de História, levando em conta principalmente o contexto curricular nacional recente.

Anteriormente, ressaltamos as premissas constitucionais transpostas para a LDB de que a educação nacional deve ser inspirada nos princípios de liberdade e nos ideais de solidariedade humana, tendo por finalidade o pleno desenvolvimento do educando, seu preparo para o exercício da cidadania e sua qualificação para o trabalho - premissas estas que devem ser aplicadas também no ensino de História. 
É importante destacar que a LDB já tem quase um quarto de século de existência e durante esse período passou por mudanças significativas. Em 2014, por exemplo, a Lei no 13.010 (Brasil, 2014) incluiu na LDB que os

Conteúdos relativos aos direitos humanos e à prevenção de todas as formas de violência contra a criança e o adolescente serão incluídos, como temas transversais, nos currículos escolares de que trata o caput deste artigo, tendo como diretriz a Lei no 8.069, de 13 de julho de 1990 (Estatuto da Criança e do Adolescente), observada a produção e distribuição de material didático adequado. (Brasil, 2017, p. 20).

Esse parágrafo estabelece um parâmetro curricular para a educação nacional de que conteúdos relativos aos direitos humanos devem ser incluídos de forma transversal no currículo. No que tange à disciplina de História, por sua característica de ciência humana, evidentemente abre espaços privilegiados para esse tipo de trabalho pedagógico - inclusive, há menções à disciplina de História na LDB que corroboram essa afirmação, conforme segue:

Nos estabelecimentos de ensino fundamental e de ensino médio, públicos e privados, torna-se obrigatório o estudo da história e cultura afro-brasileira e indígena. [...] O conteúdo programático a que se refere este artigo incluirá diversos aspectos da história e da cultura que caracterizam a formação da população brasileira, a partir desses dois grupos étnicos, tais como o estudo da história da África e dos africanos, a luta dos negros e dos povos indígenas no Brasil, a cultura negra e indígena brasileira e o negro e o índio na formação da sociedade nacional, resgatando as suas contribuições nas áreas social, econômica e política, pertinentes à história do Brasil. [...] Os conteúdos referentes à história e cultura afro-brasileira e dos povos indígenas brasileiros serão ministrados no âmbito de todo o currículo escolar, em especial nas áreas de educação artística e de literatura e história brasileiras. (Brasil, 2017, p. 21).

Para fundamentar o trabalho com as questões étnico-raciais na educação brasileira, há um capítulo das Diretrizes curriculares nacionais de educação básica (Brasil, 2013b) que trata das diretrizes curriculares nacionais para a educação das relações étnico-raciais e para o ensino de História e cultura afro-brasileira e africana, que se trata de um ponto importante quanto à reflexão 
sobre a educação em e para os direitos humanos. Frequentemente, os conteúdos curriculares ou ações pedagógicas sequer citam a expressão "direitos humanos", apesar de trabalharem com as noções referentes a ela. Ao incluir conteúdos relacionados a povos historicamente explorados e excluídos, atua-se pedagogicamente em favor dos direitos desses povos. Dessa forma, ao se discutir democracia, igualdade, liberdade, minorias e cidadania, há um trabalho sobre direitos humanos, seja na disciplina de História ou em qualquer outra.

Ainda nessa linha de discussão de currículo no âmbito da educação básica, é importante levar em conta, ainda que de forma breve, o que a Base Nacional Comum Curricular (BNCC) - a atual política de currículo da educação básica nacional - traz sobre a temática dos Direitos Humanos, em especial no ensino de história (Brasil, 2019). Em uma breve leitura do texto da BNCC, utilizando-se da ferramenta de um arquivo salvo em formato .pdf, verifica-se que a expressão "direitos humanos" é citada sessenta e quatro vezes. Do ponto de vista amplo, as citações mais relevantes, que acontecem nas diversas disciplinas, corresponde a uma das competências gerais da educação básica, segundo a qual os estudantes devem ser capazes de argumentar e defender ideias que respeitem e promovam os direitos humanos (Brasil, 2019, p. 9).

A discussão de direitos humanos é citada também na contextualização da área das ciências humanas e nas competências específicas das ciências humanas, tanto do ensino fundamental quanto do médio. No caso específico da disciplina de História, os direitos humanos aparecem de forma direta, citando a expressão em habilidades a serem desenvolvidas em vários anos diferentes e também de forma indireta, visando conhecimentos relacionados a democracia, cidadania, liberdade, igualdade e a povos que historicamente são excluídos das narrativas históricas tradicionais, tais como mulheres, negros e povos indígenas, além de diversos outros tipos de discriminações realizadas pela humanidade em múltiplos tempos históricos.

Seria oportuno analisar detidamente as formas pelas quais a BNCC (Brasil, 2019) traduz as reflexões sobre direitos humanos, mas não é este o enfoque deste artigo. O objetivo dessa reflexão foi mostrar que a educação em e para os direitos humanos está presente na legislação educacional e de currículo no que se refere ao ensino de História no Brasil.

É possível inserir nesta discussão o Plano Nacional de Educação em Direitos Humanos (Brasil, 2018), que estabelece ações para a educação básica, 
superior e informal de agentes públicos e da mídia. No que se refere a educação básica, uma das ações programáticas é

fomentar a inclusão, no currículo escolar, das temáticas relativas a gênero, identidade de gênero, raça e etnia, religião, orientação sexual, pessoas com deficiências, entre outros, bem como todas as formas de discriminação e violações de direitos, assegurando a formação continuada dos(as)trabalhadores(as) da educação para lidar criticamente com esses temas; (Brasil, 2018, p. 31).

O ensino de História é, mais uma vez, território profícuo de inclusão curricular de muitas dessas temáticas. Se "a educação em direitos humanos deve ser um dos eixos fundamentais da educação básica e permear o currículo, a formação inicial e continuada dos profissionais da educação" (Brasil, 2018, p. 30), o ensino de História pode contribuir de forma relevante. Existe, inclusive, um capítulo detalhando os fundamentos, princípios e objetivos da educação em e para os direitos humanos nas Diretrizes curriculares nacionais de educação básica (Brasil, 2013b) que reafirmam as premissas citadas acima, incluindo, assim, a disciplina de História.

A citação acima aborda também o âmbito da formação inicial. O CNE, em sua Resolução no 2/2019, define as Diretrizes Curriculares Nacionais para a Formação Inicial de Professores para a Educação Básica e institui a Base Nacional Comum para a Formação Inicial de Professores da Educação Básica, tendo como princípio norteador da organização curricular dos cursos destinados à Formação Inicial de Professores para a Educação Básica o

compromisso com a educação integral dos professores em formação, visando à constituição de conhecimentos, de competências, de habilidades, de valores e de formas de conduta que respeitem e valorizem a diversidade, os direitos humanos, a democracia e a pluralidade de ideias e de concepções pedagógicas. (Brasil, 2019, p. 5).

Essa mesma resolução cita a promoção do "respeito ao outro e aos direitos humanos" e a defesa de "ideias, pontos de vista e decisões comuns, que respeitem e promovam os direitos humanos" (Brasil, 2019, p. 13) como competências gerais docentes que devem ser desenvolvidas na formação inicial. Destaque-se que esses princípios valem, também, para a formação inicial em 
Licenciatura em História. A necessidade e importância da educação em e para os direitos humanos está fundamentada em diversos documentos curriculares e legislações que preceituam a educação de forma ampla e o ensino de História de forma específica em nosso país, tanto no âmbito da educação básica quanto no ensino superior.

Ao delinear a trajetória da educação em e para os direitos humanos no Brasil, é possível perceber que a legislação em âmbito federal que disciplina essa temática traz avanços relevantes, os quais se traduzem em políticas de currículo que incidem no ensino de História. Cabe, nesse sentido, perguntar: "Como a educação em e para os direitos humanos aparece na prática na formação destes futuros professores?"; "Esses sujeitos são de fato tocados sensivelmente pela educação em e para os direitos humanos ou se trata de uma retórica legal e jurídica?"; Quais potencialidades de formação em e para os direitos humanos o ateliê (auto)biográfico pode viabilizar no processo de preparo profissional de futuros professores de História?”. Discutiremos na próxima seção uma possibilidade de contribuição com a educação em e para os direitos humanos a partir da pesquisa-formação.

\section{O ATELIÊ (AUTO)BIOGRÁFICO COMO POTÊNCIA DE FORMAÇÃO PARA OS DIREITOS HUMANOS ${ }^{3}$}

A investigação que é base para as reflexões deste artigo se pauta nos trabalhos do campo da (auto)biografia, em que a pesquisa-formação é uma possibilidade que privilegia a perspectiva da formação dos atores participantes no decorrer da composição das narrativas, pois dispõe de várias ferramentas metodológicas, dentro das quais elegemos o ateliê (auto)biográfico como equipamento de pesquisa e de formação. De partida, a singularidade fundamental da pesquisa-formação aparece na expressão que a denomina, uma vez que se trata de um viés de investigação interligado com a formação dos sujeitos participantes. A articulação entre pesquisa e formação, teoria e prática, saberes e seres (Lapointe, 2010, p. 145), é constante e é um objetivo expresso, inclusive como uma possibilidade de inovação pedagógica (Josso, 2010), na medida em que as ferramentas de trabalho são pensadas para favorecer esse diálogo a partir de experiências individuais e coletivas com vistas a colaborar no desenvolvimento de um projeto existencial - "articulação no tempo e espaço da 
missão pessoal" (Lapointe, 2010, p. 151) na perspectiva de refletir sobre as aprendizagens e desenvolver percursos identitários profissionais. Para a pesquisadora Christine Delory-Momberger (2014, p. 325):

A metodologia empregada para atingir esse objetivo associa estritamente a pesquisa e a formação e consiste, por um lado, em elaborar um método de investigação que permita articular a análise dos fatores sociológicos e psicológicos e condicionam as histórias individuais e, por outra lado, propor aos participantes suportes de reflexão que lhes permitam analisar a sua trajetória social e as relações que mantém com sua história.

Há um elemento diferencial na pesquisa-formação que merece ser destacado, pois, como afirma Frison, "os dispositivos da pesquisa autoformativa colocam em primeiro plano a perspectiva experiencial da pessoa em formação, contribuindo para a valorização dos sujeitos cujas histórias são investigadas" (2016, p. 94); portanto, consiste em uma lógica de pesquisa em que o participante é, ao mesmo tempo, "tema" e "sujeito". Nessa lógica, os atores como subjetividades em formação devem ser valorizados e não apenas tratados como fontes de informação útil para a investigação, uma perspectiva relevante já que as personagens também têm sentimentos e pensamentos em relação à pesquisa.

Uma pesquisa (auto)biográfica e, mais especificamente, uma pesquisa-formação depende de um cabedal de narrativas. No caso específico da pesquisa-formação, o processo de construção dessas narrativas influencia diretamente no aspecto formativo da investigação. Em outras palavras, a pesquisa-formação depende da capacidade de reflexividade que o método de construção do conjunto de narrativas é capaz de proporcionar. Em nossa pesquisa, propomos a reflexão a partir da temática direitos humanos utilizando como ferramenta o ateliê (auto)biográfico.

A pesquisadora Christine Delory-Momberger (2014, p. 339) trabalha com a concepção de oficina biográfica de projeto e, com algumas adaptações relacionadas ao contexto dos sujeitos e às nossas próprias experiências, desenvolvemos o ateliê tendo como referência os trabalhos da autora. Concordamos com Conceição Leal da Costa quando ela escreve que "ao pensar a formação (do profissional) há que lembrar a pessoa, incluindo esse tempo do seu viver na sua vida inteira, de forma holística. No fundo, almejamos validar a expertise derivada da pessoa singular que se vai tornando educadora" (2018, p. 82). 
Nas páginas seguintes, buscamos descrever e teorizar o ateliê em sua potência de formação em e para os direitos humanos.

Desde o primeiro contato entre os participantes em que se promove a explicação sobre a dinâmica do ateliê e uma espécie de contrato coletivo sobre a participação nele é trabalhada a noção da formação, de construção de aprendizados em grupo, em uma perspectiva de palavra social, que tem como pontos fundamentais a liberdade e igualdade de voz e o respeito ao dito. Trata-se de um primeiro contato em que as noções de relevância e valor do outro e de sua narrativa começam a ser desenvolvidos no âmbito da pesquisa e essas construções de valorizações no processo podem também ser pensadas como direitos que são forjados em uma ratificação coletiva.

A primeira tarefa do ateliê é individual, consistindo na escrita da primeira narrativa. Os autores são estimulados a escrever essa primeira versão já sabendo que se trata de uma escrita preliminar, uma espécie de esboço para desenvolvimentos posteriores. Apresentamos os eixos de escrita a partir de algumas questões de apoio: "O que aconteceu na minha vida que fez com que eu desejasse me tornar professor(a) de História?"; "Quais conhecimentos e experiências existenciais me fizeram querer me tornar professor de História?”; "Esses conhecimentos e experiências tem relação com uma sensibilidade ao que chamamos de direitos humanos?". Tal qual a experiência relatada por Midlej e Pereira, "os focos foram as histórias de vida, especialmente pautadas na vida escolar e na ação profissional docente, em dimensões que favoreceram conexões de abertura entre o individual e o coletivo" (2016, p. 556).

Ao mesmo tempo em que visamos traçar narrativas de formação dos estudantes participantes na perspectiva de compreender suas motivações para se tornar professores de História, buscamos também compreender como a ideia de direitos humanos aparece nas narrativas. Além de identificar sensibilidades subjetivas aos direitos humanos nas razões de escolha da carreira no ensino de História estamos colocando as noções de direitos humanos em discussão e em (auto)reflexão e neste movimento de reflexividade formando-nos em e para os direitos humanos nos diálogos e socializações que a dinâmica do ateliê permite e incentiva.

A partir dos eixos citados acima, solicitamos que nessa primeira escrita os sujeitos retraçassem seus percursos de vida e caminhos formativos, buscando figuras pessoais, como familiares, amigos(as), professores e outras perso- 
nagens, além de etapas e acontecimentos, tanto positivos quanto negativos, desse itinerário em suas variadas possibilidades, seja na educação doméstica, escolar ou experiencial, ou, ainda, em seus percursos profissionais e, até mesmo, na própria experiência durante o curso de Licenciatura em História e no Pibid. Orientamos a preparação individual de cada sujeito, que pode ser uma listagem de períodos significativos e de "momentos charneira" (Josso, 2010, p. 90), ou seja, acontecimentos que representam passagens entre etapas, divisores de água nas vidas narradas, que também chamamos de "memórias de referência”. Pode ser também um texto contínuo, sem a necessidade de uma linha cronológica exata ou, ainda, uma escrita pautada em outros recursos de memória, tais como objetos pessoais, fotografias e árvores genealógicas. Então, os participantes entregam sua primeira escrita ao final do encontro, devendo considerar que, até aqui, tratou-se de uma reflexão pessoal sobre a trajetória de cada ator da pesquisa, mas que já provocou ensaios de pensamentos sobre direitos humanos que serão socializados nas próximas etapas.

A despeito de necessitar do indivíduo em seu âmbito subjetivo, a pesquisa-formação, não existe sem o coletivo, a relação social e a cumplicidade. Seja em uma entrevista narrativa ou em uma dinâmica de ateliê coletivo, por exemplo, a produção é em pares. Nas palavras de Delory-Momberger, "entram aqui as noções de coprodução, de coinvestimento segundo as quais a narrativa se constrói na relação com outrem: é feita por e com alguém, postula a cooperação de um outro cuja presença interativa (escuta, réplica) se constitui em coautor" (2014, p. 316). Ou, ainda, conforme escreveu Serge Lapointe "qualquer pessoa tem necessidade da presença do outro para compreender-se e fazer-se a si mesmo porque é em nossas relações que nos desenvolvemos" (2010, p. 160).

É essa lógica de coautoria, de produção de narrativas e formações em cumplicidade por meio de um método de pesquisa, que muda o patamar da vida narrada. Como define Delory-Momberger, "A narrativa por si só não bastaria, ela precisa entrar num dispositivo de formação pelo qual o autor da narrativa vai poder tornar-se o ator de sua história, isto é, reapropriar-se do sentido de sua vida" (2014, p. 320). Trata-se de uma relação de existência singular-plural que parte de nossa humanidade partilhada (Josso, 2010, p.70) e é colocada em jogo pelo método empregado na pesquisa-formação.

No momento seguinte, as narrativas criadas no encontro anterior são narradas em grupos de três participantes. Os participantes do pequeno grupo 
que estão na posição de escuta têm abertura para realizar perguntas de esclarecimento e detalhamento, mas com o cuidado de evitar induções e interpretações de informações na narrativa do outro participante. Para Marie-Christine Josso (2010, p. 90), nessa primeira fase de socialização oral na qual emerge a primeira narrativa

Embora inspirada na preparação anterior, toma liberdades, suscita novas recordações, tenta oferecer uma primeira interpretação do que foi formador. Assistese também a um primeiro levantamento dos fios condutores que atravessam os diferentes períodos, e que se apresentam, na maioria das vezes, como dialéticas que estruturam a relação consigo mesmo e com o mundo.

A intenção dessa possibilidade de interação durante a socialização é provocar novos níveis de reflexividade para o desenvolvimento da próxima narrativa (auto)biográfica que foi a tarefa para o encontro da semana seguinte. Essa reflexividade ocorreu no âmbito da trajetória formativa de forma ampla e na relação sensível dessa trajetória com os direitos humanos de forma estrita. Na percepção da escuta atenta, ativa e generosa do outro, entendemos a relevância política de nossa voz pronunciada como direito e ao mesmo tempo pronunciadora de direitos. Enxergamos esses momentos de caminhada para si como potenciais formativos dos futuros professores de História.

A segunda tarefa de escrita é livre e aberta. Marie Christine Josso, ao pensar sobre as produções das narrativas, escreve que elas "remetem cada participante para um trabalho solitário, mas, largamente habitado pelo diálogo com outra narrativa, ou outras narrativas ouvidas, e a partilha do que foi experimentado durante as etapas precedentes" (2010, p. 93), o que nos levou a entender que o método traz também a escuta como um potencial formativo relevante dentro do todo que é o ateliê. Em outras palavras, tratou-se de interrogar o conhecimento sobre si mesmo com base na lógica de semelhanças e diferenças ocasionadas pelo contraste com a narrativa do outro acessada, sobretudo, a partir da escuta atenta e generosa. A narrativa, assim, tem como seu par inseparável a escuta e entendemos ambas como direitos relacionados à dignidade humana.

No próximo encontro, acontece a socialização da narrativa solicitada como tarefa no encontro anterior e, dessa vez, a socialização é para todos os participantes do ateliê. Conforme escreve Delory-Momberger (2014, p. 341): 
Este trabalho comum de elucidação da narrativa visa ajudar o autor a construir sentido em sua história de vida e os narratários a compreender essa história do exterior como fariam com um romance ou com um filme. O narrador é assim levado a adequar sem cessar sua história na lógica das exigências narrativas impostas do exterior.

Se há uma perspectiva de elucidação coletiva, há, ao mesmo tempo, a formação coletiva, inclusive para os direitos humanos. Na etapa em questão, o método preconiza uma ação interessante, vez que cada sujeito, antes de começar a sua narração, escolhe um participante para ser seu "secretário" - escriba -, que deve registrar as narrações da pessoa que lhe foi incumbida e as interpelações dos outros participantes. O relato do escriba deve ser em primeira pessoa do singular e, ao final de cada sessão, o texto é entregue ao seu destinatário. Esse procedimento previsto no ateliê é interessante por representar uma (auto)formação com base em uma perspectiva de alteridade, que é, também, fundamental para a compreensão e exercício da educação em e para os direitos humanos. A respeito da escrita do relato por um terceiro, Christine Delory-Momberger indica que

Se insere de novo na perspectiva de coerência narrativa enunciada acima e "objetiva" aos olhos de seu autor/ator a história de sua própria vida. O processo de apropriação de sua história, comum ao conjunto das práticas de histórias de vida", passa aqui pela incursão compreensiva do outro e pelo distanciamento de si mesmo. (2014, p. 342).

Esse trabalho e aprendizado em coautoria se dá não somente nos momentos de narração, mas também nos momentos de escuta, por meio do aprendizado com a narrativa do outro. Em outras palavras, trata-se de uma cointerpretação geral do acervo de narrativas construído na relação estabelecida pelos sujeitos, já que as aprendizagens e, mais especificamente, as aprendizagens profissionais, não são lineares, mas, na verdade, multicontextuais, experienciais, plurais, complexas e contínuas (Monteiro et al., 2010, p. 195).

A etapa final reside na síntese. Novamente em trios, o projeto pessoal de cada participante é coexplorado e, em reunião coletiva, cada participante apresenta e defende o seu projeto (auto)biográfico na perspectiva de produção de estados diferentes de ser e aberturas para novas construções de si (Midlej; Pereira, 2016, p. 556), uma vez que, conforme reflete Josso (2010, p. 99), 
Esse movimento retrospectivo do pensamento provoca tomadas de consciência, tanto pela pluralidade de leituras possíveis de uma mesma experiência, como pela evolução geral daquilo a que chamo de visão de mundo ou, cosmogonia pessoal, que cada um progressivamente construiu e interiorizou diante das suas necessidades de dar sentido à sua vivência, à sua trajetória, aos seus laços consigo mesma, com o outro e com o meio humano e natural.

Ao fim do ateliê, a contrapartida formativa do processo produzido é a possibilidade de visualização do nosso itinerário de vida, bem como de nossos investimentos e objetivos. Com isso, evidencia-se a possibilidade de desenvolvimento de um autoorientação, uma invenção de si, articulando conscientemente heranças, experiências formadoras, pertenças, valorizações, desejos, imaginários e oportunidades socioculturais, sobretudo, no que se refere à docência em e para os direitos humanos (Josso, 2010, p. 65).

Esse caráter formador do ateliê funciona não somente para os participantes, mas também para os pesquisadores-mediadores. Convém relatar que a dinâmica do ateliê é formativa para o pesquisador também por conta de sua lógica de intercalação de atividades que exigem o desenvolvimento de habilidades de gestão de grupo, pois, como escreve Josso, "Essa alternância exige igualmente do pesquisador-formador uma capacidade de atenção bifocal simultaneamente sobre as pessoas em formação e sobre o grupo" (2010, p. 197).

$\mathrm{O}$ ateliê (auto)biográfico, desenvolvido a partir das ferramentas metodológicas descritas e problematizadas nesta seção, tem, ao nosso ver, a potência de desenvolver (auto)reflexões formativas a respeito dos direitos humanos valorizando a narrativa de vida e contribuindo para a formação de professores de História no sentido de desenvolver destrezas na educação em e para os direitos humanos.

CONSIDERAÇÕES SOBRE ENSINO DE História, NARRATIVAS E DIREITOS HUMANOS

Ao indicar os caminhos da educação em e para os direitos humanos no Brasil, foi possível perceber potencialidades dessa categoria de educação e formação ao menos no que se refere à esfera formal, isto é, legislativa, jurídica e de currículo. A partir dessa constatação, buscamos empreender reflexões no 
sentido de compreender o ateliê (auto)biográfico como dispositivo potente na formação de professores História em e para os direitos humanos do ponto de vista prático e operacional, levando em conta que o respeito aos direitos humanos faz parte das competências gerais docentes que devem ser desenvolvidas na formação inicial para a docência.

A narrativa de si, seja ela desenvolvida a partir de um ateliê ou por qualquer outra ferramenta metodológica que permita exercícios reflexivos e dialógicos sobre as experiências de vida, é um recurso formativo que fornece importantes possibilidades práticas. Para estudantes de Licenciatura em História e professores em formação, antes de uma identidade profissional existem as trajetórias, experiências e memórias de cada indivíduo. O processo de construção dessas narrativas tende a usar essas próprias vivências e lembranças individuais em favor da formação de cada sujeito já que "o próprio esforço de explicitação, encadeamento e organização de uma certa trajetória de vida, contribui para um processo de tomada de consciência individual e coletivo" (Henriques, 2018, p. 44).

Ao considerar o ateliê como capaz de promover a formação em e para os direitos humanos, levamos em conta que ele pode proporcionar uma "concepção de formação como autoformação, na qual o sujeito, ao viver experiências de si, tende a produzir forças vitais criadoras de estados inéditos de ser, ao rearranjar-se, identificar-se e diferenciar-se em fontes inesgotáveis de sentidos" (Midlej; Pereira, 2016, p. 561). A ideia é que, no processo de biografização, mesmo não tendo a possibilidade de mudar os acontecimentos, a pessoa que narra tenha a oportunidade de desenvolver reinterpretações, novos enredos, dessa forma se reinventando (Passeggi; Souza, 2017, p. 8). Ou seja, para além de se implicar no narrado, os sujeitos imaginam novas formas de realizar o vivido, construindo outros horizontes de possibilidades. A experiência narrada e refletida é, assim, o ponto central dessa modalidade de pesquisa, havendo, portanto, na formação, um trabalho sobre si; no caso deste trabalho, relacionado aos direitos humanos.

Confiamos que, no processo de desenvolvimento do ateliê, se constrói a expectativa e a prática de um desfecho formativo para os sujeitos participantes da pesquisa. É possível pensar esse desfecho como uma contrapartida pela generosidade da participação, mas é necessário refletir e afirmar que a formação em si não é uma garantia. Trata-se, sim, de uma decorrência viável da autoin- 
vestigação. Ela é uma possibilidade subjetiva, a depender das intencionalidades e do grau de reflexividade que o sujeito participante investir no processo.

Os efeitos transformadores são, enfim, aleatórios já que são subordinados ao pensamento reflexivo de cada sujeito (Josso, 2010b, p. 172). Como escrevem Jussara Midlej e Marcos Villela Pereira (2016, p. 560):

As narrativas (auto)biográficas, ao ocorrerem como processos metaformativos, a partir de perspectivas relacionais, linguísticas e reflexivas, apresentaram a história acontecendo como possibilidade de transformação; demonstraram a provocação de desarranjos e rearranjos, nas itinerâncias pessoais e profissionais .

Marca-se, assim, que o sucesso do ateliê em seu âmbito formativo depende da intencionalidade. Conforme escreve a professora Maria Helena Menna Barreto Abrahão, "A intencionalidade é a dimensão indispensável nesse processo. No limite, sem intenção, não há formação. Pode haver informação. Formar-se requer um esforço conscientemente desejante pelo educando e pelo educador, este que nesse processo também se educa" (2016, p. 29). A intencionalidade é, nesse contexto, uma conduta individual. É nas experiências do indivíduo que o método associado à pesquisa-formação precisa tocar. Para Delory-Momberger, "Essa consideração da experiência individual se insere num processo global que associa estritamente as pessoas ao processo formativo e as considera como atores integrais de sua própria formação" (2014, p. 315).

Outro aspecto relevante a se levar em conta é que os processos da pesquisa são experiências formativas de mão dupla, o que significa que "o pesquisador também se implica e se coloca como um sujeito da pesquisa e se torna mais um elo em uma comunidade de narrativas suscitada nesse processo" (Henriques, 2018, p. 43) e que os professores-pesquisadores responsáveis pelo ateliê têm grande importância na formação em e para os direitos humanos destes futuros professores. Essa mão dupla formativa gera uma sensação de múltipla generosidade nos atos de investigação e instrução, já que, em alguma medida, a hierarquia pesquisador-sujeitos se torna tênue em alguns momentos e movimentos do processo. Isso significa que as trocas de experiências e ideias nos processos do ateliê tendem a ser satisfatórios do ponto de vista formativo para ambos os lados. Tem-se, assim, um processo coletivo da construção compartilhada de um saber singular.

No ateliê, por fim, oferece-se "considerar o ser humano como um sujeito- 
-ator singular-plural de sua vida, capaz de ser um interlocutor ativo, inclusive num processo de pesquisa" (Josso, 2010, p.70) na medida em que ela permite visualizar itinerário de vida, investimentos e objetivos com base numa invenção de si que articula heranças, experiências, pertenças, valorizações, desejos, imaginário e oportunidades para transformar a vida em uma obra inédita, a ser construída guiada por uma lucidez, buscando despertar a autopoiese, autoorientação e autoformação (Josso, 2010, p. 65).

Essa busca de uma invenção de si pode e precisa ser refletida a partir de um universo mais amplo; afinal, para que se reinventar? Serge Lapointe afirma que nos reinventamos para alcançar a emancipação - em suas palavras: "assinar a sua vida como um ator e tornar-se responsável é um projeto eminentemente precioso para qualquer ser humano que se põe a caminho da liberdade" (2010, p. 159). Ao buscar se formar a partir desses pressupostos, há a realização de uma ação coletiva com efeitos individuais na qual são interrogadas as trajetórias particulares, mas também as trajetórias da sociedade como um todo (Lapointe, 2010, p. 161) e a pretensão é que essa trajetória leve para um caminho de formação e docência que valorize a educação em e para os direitos humanos.

\section{REFERENNCIAS}

ABRAHÃO, Maria Helena Menna Barreto. Intencionalidade, reflexividade, experiência e identidade em pesquisa (auto)biográfica: dimensões epistemo-empíricas em narrativas de formação. In: BRAGANÇA, Inês Ferreira de Souza; ABRAHÃO, Maria Helena Menna Barreto; FERREIRA, Márcia Santos (org.). Pesquisa (Auto)biográfica: conhecimentos, experiências e sentidos. Curitiba: CRV, 2016. p. 29-50.

BERKENBROCK-ROSITO, Margarete May. No espaço da narrativa de si. In: FONTOURA, Helena Amaral da; MONTEIRO, Isabel Alice Oswald; CHAVES, Lelis Iduina Mont'Alverne. Espaços formativos, memórias e narrativas. Curitiba: CRV, 2014. p. 187-202.

BRASIL. Resolução CNE/CP no 1, de 30 de maio de 2012. Estabelece Diretrizes Nacionais para a Educação em Direitos Humanos. Diário Oficial da União, Brasília, DF, 30 maio 2012. Disponível em: http://portal.mec.gov.br/dmdocuments/rcp001_12. pdf. Acesso em: 22 jul. 2020.

BRASIL. Caderno de educação em direitos humanos. Educação em direitos humanos: diretrizes nacionais. Brasília, DF: Ministério da Educação, 2013a. Disponível em: http:// 
portal.mec.gov.br/index.php?option $=$ com_docman\&view=download \&alias =32131-educacao-dh-diretrizesnacionais-pdf\&Itemid=30192. Acesso em: 22 jul. 2020 .

BRASIL. Diretrizes curriculares nacionais da educação básica. Brasília, DF: Ministério da Educação, 2013b. Disponível em: http://portal.mec.gov.br/index. php?option $=$ com_docman \&view $=$ download $\&$ alias $=13448$-diretrizes-curiculares-nacionais-2013-pdf\&Itemid=30192. Acesso em: 22 jul. 2020.

BRASIL. Lei no 13.010, de 26 de junho de 2014. Altera a Lei no 8.069, de 13 de julho de 1990 (Estatuto da Criança e do Adolescente), para estabelecer o direito da criança e do adolescente de serem educados e cuidados sem o uso de castigos físicos ou de tratamento cruel ou degradante, e altera a Lei no 9.394, de 20 de dezembro de 1996. Diário Oficial da União, Brasília, DF, 27 jun. 2014. Disponível em: http://www. planalto.gov.br/ccivil_03/_Ato2011-2014/2014/Lei/L13010.htm. Acesso em: 22 jul. 2020.

BRASIL. Constituição da República Federativa do Brasil. Brasília, DF: Senado Federal, 2015. Disponível em: https://www2.senado.leg.br/bdsf/bitstream/handle/ id/508200/CF88_EC85.pdf?sequence=1\&isAllowed=y. Acesso em: 22 jul. 2020.

BRASIL. $L D B$ : Lei de diretrizes e bases da educação nacional. Brasília, DF: Senado Federal, 2017. Disponível em: https://www2.senado.leg.br/bdsf/bitstream/handle/ id/529732/lei_de_diretrizes_e_bases_1ed.pdf. Acesso em: 22 jul. 2020.

BRASIL. Plano Nacional de Educação em Direitos Humanos. Brasília, DF: Ministério dos Direitos Humanos, 2018. Disponível em: https://www.gov.br/mdh/pt-br/navegue-por-temas/educacao-em-direitos-humanos/DIAGRMAOPNEDH.pdf. Acesso em: 22 jul. 2020.

BRASIL. Base Nacional Comum Curricular: educação é a base. Brasília, DF: Ministério da Educação, 2019. Disponível em: http://basenacionalcomum.mec.gov.br/images/BNCC_EI_EF_110518_versaofinal_site.pdf. Acesso em: 22 jul. 2020.

BRASIL. Resolução CNE/CP no 2, de 20 de dezembro de 2019. Define as Diretrizes Curriculares Nacionais para a Formação Inicial de Professores para a Educação Básica e institui a Base Nacional Comum para a Formação Inicial de Professores da Educação Básica (BNC-Formação). Diário Oficial da União, Brasília, DF, 23 dez. 2019. Disponível em: http://portal.mec.gov.br/docman/dezembro-2019-pdf/135951-rcp002-19/file. Acesso em: 22 jul. 2020.

COSTA, Conceição Leal da. Traços de vida e $(\mathrm{m})$ narrativas de (trans)formação. In: FURLANETTO, Ecleide Cunico; NACARATO, Adair Mendes; GONÇALVES, Terezinha Valim Oliver (org.). Espaços formativos, trajetórias de vida e narrativas docentes. Curitiba: CRV, 2018. p. 73-98.

DELORY-MOMBERGER, Christine. As histórias de vida: da invenção de si ao projeto de formação. Natal: UFRN; Porto Alegre: PUCRS; Salvador: UNEB, 2014.

FRISON, Maria Lourdes Bragagnolo. Narrativas de professores iniciantes - ex-bolsis- 
tas do PIBID: dispositivo de formação articulado à autorregulação da aprendizagem. In: VICENTINI, Paula Perin; CUNHA, Jorge Luiz da; CARDOSO, Lilian Auxiliadora Maciel (org.). Experiências formativas e práticas de iniciação à docência. Curitiba: CRV, 2018. p. 89-104.

HENRIQUES, Eda Maria de Oliveira. Dimensões subjetivas, sociais e formativas do aporte (auto)biográfico em educação: alguns aspectos epistemológicos e metodológicos. In: FURLANETTO, Ecleide Cunico; NACARATO, Adair Mendes; GONÇALVES, Terezinha Valim Oliver (org.). Espaços formativos, trajetórias de vida e narrativas docentes. Curitiba: CRV, 2018. p. 43-54.

JOSSO, Marie-Christine. As narrações do corpo nos relatos de vida e suas articulações com os vários níveis de profundidade do cuidado de si. In: VICENTINI, Paula Perin; ABRAHÃO, Maria Helena Menna Barreto (org.) Sentidos, potencialidades e usos da (auto)biografia. São Paulo: Cultura Acadêmica, 2010. p. 171-192.

LAPOINTE, Serge. Encontro de si em história de vida: o aporte das histórias de vida na formação em "sentidos e projetos de vida". In: VICENTINI, Paula Perin; ABRAHÃO, Maria Helena Menna Barreto (org.) Sentidos, Potencialidades e Usos da (auto)biografia. São Paulo: Cultura Acadêmica, 2010. p. 145-167.

MAUÉS, Antonio; WEYL, Paulo. Fundamentos e marcos jurídicos da educação em direitos humanos. In: SILVEIRA, Rosa Maria Godoy et al. Educação em direitos humanos: fundamentos teórico-metodológicos. João Pessoa: UFPB, 2007.

MIDLEJ, Jussara; PEREIRA, Marcos Villela. As histórias de vida como tramas de fios na composição da professoralidade. Revista Brasileira de Pesquisa (Auto)Biográfica, Salvador, v. 1, n. 3, p. 551-563, 13 dez. 2016. Disponível em: http://www.revistas.uneb.br/index.php/rbpab/article/view/3004. Acesso em: 22 jul. 2020.

MONTEIRO, Filomena Maria Arruda et al.. Narrativas de formação-investigação como lugar de aprendizagens em contexto colaborativo. In: VICENTINI, Paula. Perin; ABRAHÃO, Maria Helena Menna Barreto (org.) Sentidos, Potencialidades e Usos da (auto)biografia. São Paulo: Cultura Acadêmica, 2010. p. 193-210.

ONU. Diretrizes para a formulação de planos nacionais de ação para a educação em direitos humanos. Genebra: ONU, 1997. Disponível em: http://www.dhnet.org.br/ dados/pp/edh/mundo/onu_diretrizes_planos_nac.pdf. Acesso em: 22 jul. 2020.

ONU. Plano de ação: Programa Mundial para Educação em Direitos Humanos. Brasília, DF: 2012. Disponível em: http://www.dhnet.org.br/dados/textos/edh/br/plano_acao_programa_mundial_edh_pt.pdf. Acesso em: 22 jul. 2020.

PASSEGGI, Maria da Conceição; SOUZA, Elizeu Clementino de. O movimento (auto) biográfico no Brasil: esboço de suas configurações no campo educacional. Investigación Cualitativa, Madri, v. 2, n. 1, p. 6-26, 2017.

SADER, Emir. Contexto histórico e educação em direitos humanos no Brasil: da dita- 
dura à atualidade. In: SILVEIRA, Rosa Maria Godoy et al. Educação em direitos humanos: Fundamentos teórico-metodológicos. João Pessoa: UFPB, 2007. p. 75-83

SILVA, Aida Maria Monteiro; TAVARES, Celma. Educação em direitos humanos no Brasil: contexto, processo de desenvolvimento, conquistas e limites. Educação, Porto Alegre, v. 36, n. 1, p. 50-58. jan./abr. 2013. Disponível em: https://revistaseletronicas.pucrs.br/ojs/index.php/faced/article/view/12315. Acesso em: 22 jul. 2020.

SOUSA, Nair Heloisa Bicalho de. Trajetória histórica e desafios da educação em direitos humanos no Brasil e na América Latina. Revista Esmat, Palmas, v. 9, n. 13, p. 87-102, 19 dez. 2017. Disponível em: http://esmat.tjto.jus.br/publicacoes/index. php/revista_esmat/article/view/200. Acesso em: 22 jul. 2020.

TOSI, Giuseppe; FERREIRA, Lúcia de Fátima Guerra. Educação em direitos humanos nos sistemas internacional e nacional. In: FLORES, Elio Chaves; FERREIRA, Lúcia de Fátima Guerra; MELO, Vilma de Lurdes Barbosa (org.). Educação em direitos humanos \& educação para os direitos humanos. João Pessoa: UFPB, 2014. p. 37-63.

\section{NOTAS}

${ }^{1}$ Esta pesquisa conta com financiamento da Coordenação de Aperfeiçoamento de Pessoal de Nível Superior (Capes) por meio de uma bolsa de doutorado. Na pesquisa e no artigo, utilizamos várias denominações para se referir aos sujeitos da pesquisa: participantes, personagens, atores, autores e sujeitos. A escolha dessa diversidade de termos tem relação com as reflexões de Josso (2010) sobre o caráter ativo e criativo necessário aos participantes de uma pesquisa-formação.

${ }^{2}$ A pesquisa de doutorado "Narrativas de Vida e formação docente: bolsistas do PIBID em História e suas identificações com os Direitos Humanos" está em desenvolvimento no âmbito do grupo de pesquisa Subjetividades de (Auto)biografias, vinculado ao Programa de Pós-Graduação em Patrimônio Cultural e Socidade da Universidade da Região de Joinville - UNIVILLE. O objetivo central da investigação é compreender, nas narrativas de vida dos estudantes em formação, como suas subjetividades são construídas sensíveis aos Direitos Humanos.

${ }^{3} \mathrm{O}$ ateliê problematizado nesta seção do artigo envolvendo os sujeitos da pesquisa seria realizado no primeiro semestre de 2020, mas ele foi adiado por conta das recomendações de distanciamento físico provocadas pela pandemia do novo coronavírus (Covid-19).

Artigo recebido em 30 de julho de 2020. Aprovado em 16 de setembro de 2020. 